\title{
Hybrid Regenerative System on Power Electronic Transformer for Electric Traction Applications
}

\author{
Sachin Gee Paul, CS Ravichandran
}

\begin{abstract}
Regenerative braking has been playing a significant role in electric locomotives to overcome dissipation of the kinetic energy as heat. For high-speed rail topologies, Power electronic transformer based locomotive has the only solution to achieve it. For the isolation purpose and to reduce the weight of the locomotive, a feasible method by substituting loco transformer with a transformer with high frequency design. With the increasing awareness of energy consumption more electrified locomotives now moving to "Green Energy ". This paper aims to describe the importance of hybrid electric locomotive system when compared to conventional one. By integrating the regenerative braking on power electronic transformer with a storage medium will be a promising solution for the future high-speed rails. The simulation of IGBT based dc to dc converter with traction inverter with storage medium has simulated from MATLAB/SIMULINK platform.
\end{abstract}

Keywords : Line Frequency Transformer (LFT, Power Electronics Transformer (PET), State of Charge(SOC), Variable Voltage Variable Frequency(VVVF), Voltage Source Inverter (VSI)

\section{INTRODUCTION}

Regenerative braking technology is a core area for increasing the energy efficiency of the various electric vehicles. Recently most of the system equipped with some energy storage mediums, such as a battery and an ultra-capacitor. Various studies showed that hybrid electric vehicles have achieved their fuel efficiencies by $30-40 \%$, during regenerative braking mode. However, the braking force required by a driver cannot be assured through regenerative braking alone, due to some limitations, such as vehicle speed and battery SOC (state of charge). The braking process of pure electric vehicles is completed by the combination of regenerative braking mode and mechanical braking to overcome friction.

Revised Manuscript Received on December 30, 2019.

* Correspondence Author

Sachin Gee Paul*, Research Scholar, Department of Electrical \& Electronics Engineering,Sri Ramakrishna Engineering College, Coimbatore,sachingeepaul@gmail.com

Dr.CS Ravichandran, Professor,Department of Electrical \& Electronics Engineering, Sri Ramakrishna Engineering College,Coimbatore eniyanravi@gmail.com

(c) The Authors. Published by Blue Eyes Intelligence Engineering and Sciences Publication (BEIESP). This is an open access article under the CC BY-NC-ND license (http://creativecommons.org/licenses/by-nc-nd/4.0/)
History of locomotives originated from the steam propulsion system. After years of research, a wide development in the field of internal combustion engine plays a key role in rolling stock technology. Earlier diesel locomotives are widely used for rail transportation, now recent locomotives drives purely based on electric motors but in the case of non-electric locomotives, a prime mover attached to traction motor in which the propulsion of prime mover purely based on the performance of internal combustion engine. The braking system is very essential to reduce or stops the speed of motors for electrical as well as a mechanical system. Various types of braking are applied based on the types of the motors with their operations. The performance behavior of each motor are different from each other, hence these braking methods are divided into three parts mainly, regenerative braking, plugging type braking and dynamic braking. In Regenerative braking when the speed of the motor exceeds the synchronous speed the regenerative mode begins. During this mode, the motor works as a generator and the power is returned back to the grid. When the rotor rotate above the synchronous speed, then the machine runs as generator ,the current and torque reverses thus counter torque act on the axle of the machine thus braking takes place. When the machine run at super-synchronous speed which may create damage mechanical side and electrically also, this issue can overcome by if the variable frequency source is available. Regenerative braking mode can be operated at sub synchronous speed. In many literatures PETs, based technologies were discussed for the performance of electric vehicles. This paper is mainly focusing on the performances of a high-speed locomotive with PET configuration were discussed. The conventional line frequency transformer (LFT) is used commonly in electric locomotives for the isolation and voltage regulation but the major drawback for this LFT is weight [1]. Since due to the low operating frequency, LFTs are bulky and heavy .This LFT is the major weight contributor for a locomotive. Line frequency transformers (LFTs) in railway vehicles are usually enhanced for minimum power density $(0.25-0.35$ $\mathrm{kVA} / \mathrm{kg}$ ), and efficiency around $94 \%$ for $25 \mathrm{kV} / 50 \mathrm{~Hz}$ traction systems. The increase in demand for railway vehicles executes constraints on size, weight, and efficiency of the traction equipment with optimized manner [2]. The better use of new insulation materials, synthetic ester oil as dielectric, design of windings, and coolants may not suitable to fully address the issues. 


\section{Hybrid Regenerative System on Power Electronic Transformer for Electric Traction Applications}

The recent trends power electronic switches with high voltage braking capability and ability to hold greater voltage stress will risen to a substantial increase in the market share of PWM controlled voltage source converters (VSC). Since because of huge tractive load it is very essential to meet high load current flowing through the power switches. Thus IGBT holds the key role in fulfilling the demands because of the unique characteristics. The high-speed rail is the system which includes specially designed rolling stock and tracks to achieve greater speed for locomotives. In Future, new lines with running speed above 350 kilometers per hour widely which uplift the conventional locomotives in existing lines run with a maximum of 130 kilometers per hour. Many literatures discussed about transformer less conversion stage operation on locomotive [3-4]. The input initial stage consists of a cascaded $\mathrm{H}$ bridge converter with four series-connected drives. The main drawback regarding direct transformerless operation is insulation and protection concept, if any failure occurs in any part of the module it will affect the entire unit. So isolation of the power stage is important for the case of locomotive operation.

In this paper, hybrid technologies with the integration of power electronic transformer with traction motors were discussed. A high voltage $25 \mathrm{kV} 50 \mathrm{~Hz}$ single phase ac catenary voltage is directly fed to PET-based locomotive drive. The section II discuss about importance of regenerative braking system for electric locomotives and also discuss about the merging of various renewable energy source with traction power substation. The section III discuss about the necessity of power electric transformer based converters with hybrid configuration for high speed rail networks and finally section IV discuss about various results obtained from MATLAB Simulink platform .

\section{STRUCTURE OF REGENERATIVE BRAKING SYSTEM FOR LOCOMOTIVES}

Energy saving on locomotives can achevied during the acceleration mode at the time when locomotive are moving free run. This energy is "stored" as kinetic and potential energy and can be redistributed into electric energy by changing the operating mode of the electrical machine from motor-mode to the generator-mode during the time of braking. This recovered electrical energy can be transmitted backward with the suitable conversion with converters and return back to the grid. Thus energy from one locomotive can be utilized for other locomotives during the time of regeneration. This system is normally employed for all railway system. Figure 1 shows the power flow scheme of the regenerative braking mode. Many of the literature describe about regenerative braking with storage medium on urban rail transportation. An ultra capacitor based control method strategy will improves system efficiency .In order to improve reliability and avoid high speed commutation recently droop control can be adopted [5-6].

\section{A. Energy Storage Medium on Locomotive}

The design of a storage device is so important for hybrid vehicles. The main limitation of battery storage is storing time is more as well as the power density is less even though it has greater storage capacity. As the power rating increase the size of the battery increases. So it is not suited for the battery alone as a storage medium for high power application.

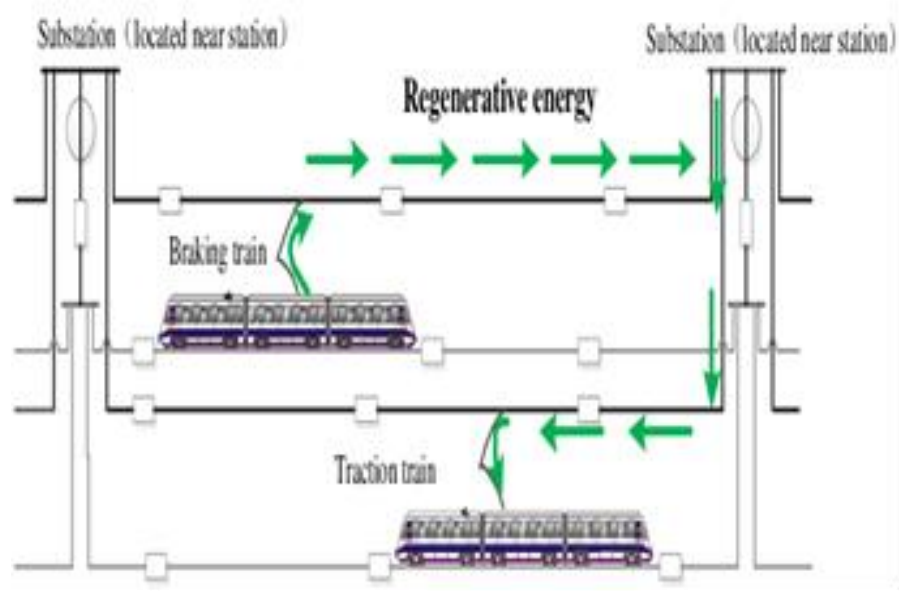

Fig. 1. Regenerative Braking Scheme for Locomotives

The performance of the ultra-capacitor is different from the battery. The unique characteristics of the ultra-capacitor are to overcome the problems of conventional methodology. Since power density is very high but it has negligible storage capacity [7].The combination of two characteristics of battery and ultra-capacitor is utilized for the high power storage applications like hybrid vehicles. By using the ultra-capacitor model, increase the lifetime of the battery in addition to that it also increases the speed of the vehicle and store energy during the regeneration mode of the vehicle.

\section{B. Electric Locomotive Traction Motor Power}

The performance of traction motors mainly consider based on the torque and speed characteristics. The traction motors in locomotives are also designed to operate to withstand environment conditions, for this to meet rugged physical construction is required. The traction motor loading depends on the start-stop operation of locomotive duty cycles for small time interval operations.[8] Generally, for a locomotive traction motor characteristics is classified into various operating modes (a) torque -acceleration at maximum, (b) power- acceleration at maximum, (c) constant- speed, (d) coasting (e) braking. This five operating mode charcterstics as shown on Figure 2.

For a traction motor driving condition, high tractive effort is supplied to motor load end at starting. Thus motor is operating at maximum torque mode. By considering the parameters like gravity gradient force and resistance of wind the maximum speed with maximum load is determined. Moreover, the braking effort efficiency also depend on the use of mechanical as well as electric braking scheme.

High starting torque is the unique feature for traction motors. Recently ac induction motor has a similar characteristic provided in dc motors used earlier. When the machine reach the desired speed, the supply frequency also be increased with respect to rotational frequency provided it maintains net difference, equal to slip frequency. 
The induction motor need an external source, and a dc motor has its own commutator segment. The commutator in dc motor acts as a mechanical inverter in addition to this dc motor require well maintenance on each parts. Table I compares the different performance characteristics of different types of traction machine.

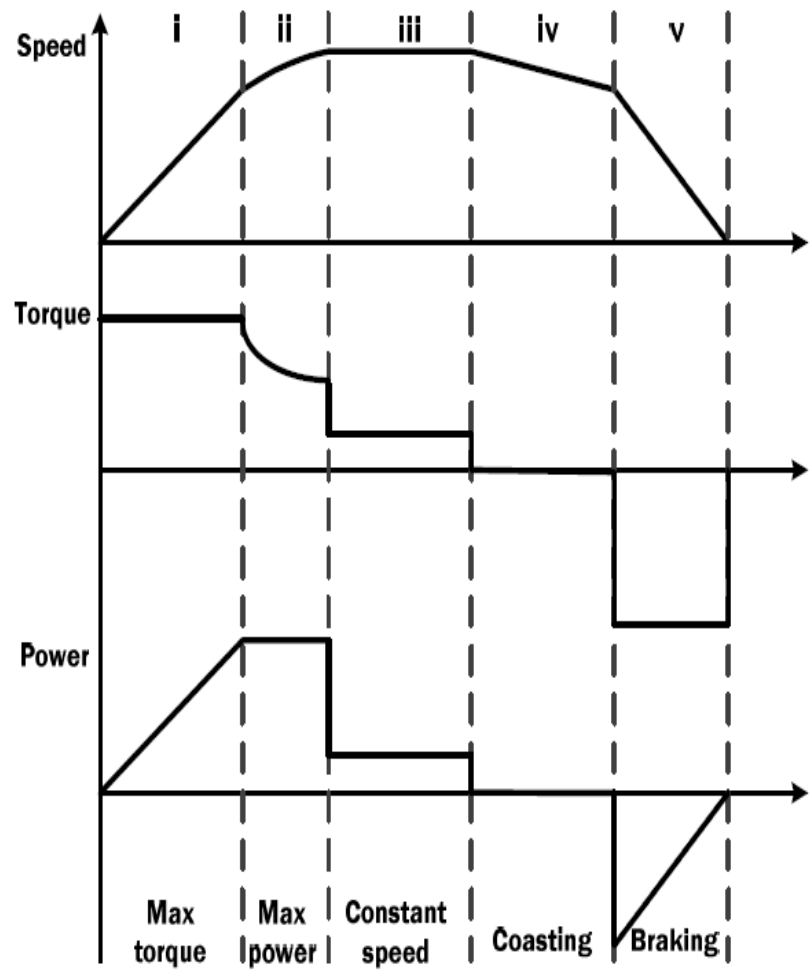

Fig. 2.Locomotive Operation Scheme

\begin{tabular}{|c|c|c|c|c|c|}
\hline & DC & Synchronous & Induction & PMSM & SRM \\
\hline $\begin{array}{c}\text { Maximum } \\
\text { speed }\end{array}$ & Medium & High & Highest & High & Highest \\
\hline $\begin{array}{c}\text { Torque } \\
\text { density }\end{array}$ & Low & High & High & Highest & High \\
\hline Efficiency & Medium & High & High & Highest & High \\
\hline Reliability & Low & Medium & High & High & Highest \\
\hline Cost & Medium & Medium & Medium & Highest & Medium \\
\hline
\end{tabular}

Table I Performance characteristics of different types of traction machine.

\section{Integrating with Renewable Energy Sources on Traction Substation}

Traffic density of railway network increases means energy consumption of locomotives increases .The only solution is to conserve energy by hybridizing the traction substation with more than one source. For avoid the overloading operation on traction substation by combining two or more renewable sources. A battery storage medium is also integrated with substation is essential. The purpose of the storage medium is to meet the peak power and consumes the excess of regenerative power developed on the converter line side to the grid [9-13]. The overall power consumed by the locomotive is Renewable Energy Power, Battery Power and Traction substation Power on (1)

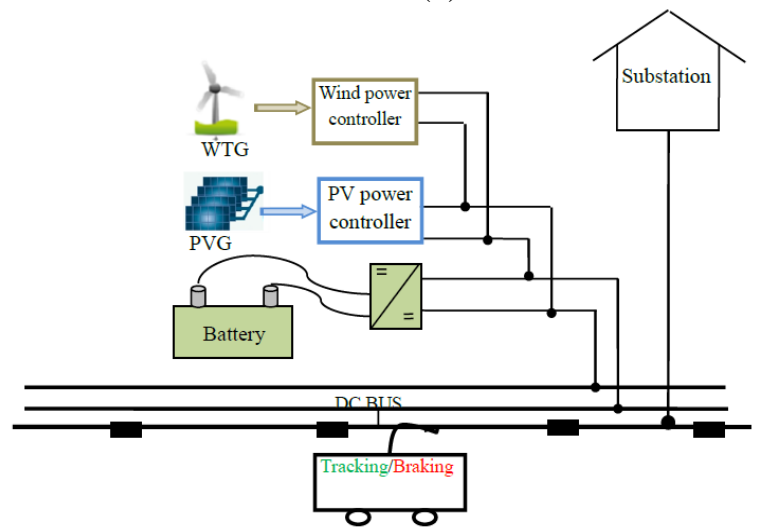

Fig.3 Integrating with Reneweable Energys

$P_{\text {Train Consumed }}=P_{\text {Renewable sources }}+P_{\text {Battery }}+T_{\text {traction Substation }}$ (1)

The Figure 3 shows the hybrid architecture integrated with wind ,PV and battery storage on traction substation. In Hybrid energy system it is essential to store the excess energy in storage medium with ultra-capacitor. The battery and ultra-capacitor differ on their power density and energy availability .The high life cycle span is the main advantage of ultra-capacitor .The another advantage is to capture peak energy with fast response. Because of these reasons ultra-capacitor is most suitable for high frequency operation for regenerative braking with high power density [14-15].

D. Variable Voltage Variable Frequency on Locomotive.

The synchronous speed can be control on induction motor by controlling the number of poles in the motor and the supply frequency . Torque is developed by a combination of rotor slip with excitation current in the stator. The change of "volts per hertz" ratio of motor windings results depend upon the motor strength. The symmetrical operation is achieved in either regenerative region or motoring region. By applying the proper tuning parameters of frequency, slip, and current maximum load torque can be achieved. The slip-torque characteristics changes with each motor design configurations as shown in Figure 4 . For controlling asynchronous machine, a shaft encoder is used to predict to calculate or actually measure rotor slip To vary the frequency an electronic inverter is used. In order to control the motor more preciously the vector control method is normally used for fine tuning and essentially means that algorithms within the inverter are calculating the relative positions of stator -rotor voltage, current and magneto motive force with forming some algorithmic sequence. The main contribution of vvvf drives on electric vehicles during the regeneration mode. Normally all-electric vehicles under regeneration mode run at a super-synchronous mode which results on some mechanical as well as electrical failure. In order to overcome this regeneration mode of the motor should operate in sub synchronous speed with the aid of a variable voltage variable frequency scheme.

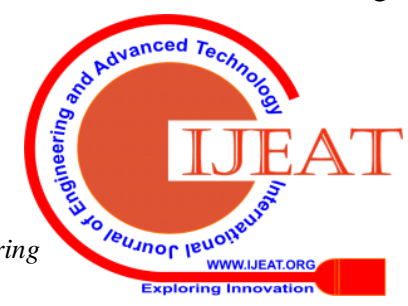




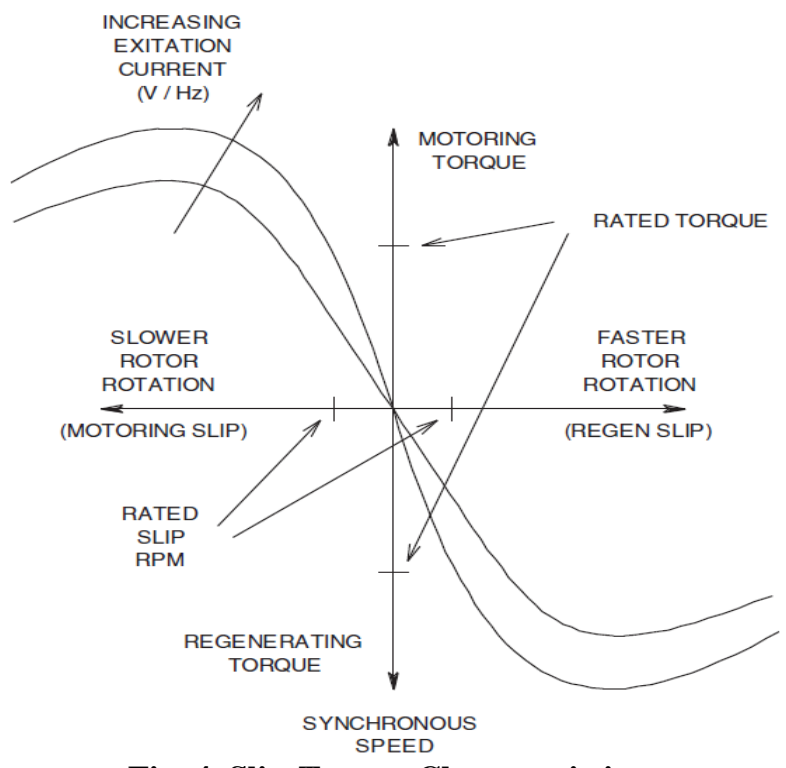

Fig. 4. Slip-Torque Characteristics

\section{OUTLINE OF POWER ELECTRONIC TRANSFORMER BASED LOCOMOTIVES}

Modern electric locomotive uses various configurations of power converters. A lot of researchers doing in the field of energy efficient locomotives for the high-speed rail system. Earlier internal combustion engines are connected to the axle for driving locomotives. In fully electric powered locomotive only electric motors play a key role. A line frequency transformer inside the locomotive feeds all the associated converter with motor drives. Figure 5 shows the conventional block diagram of an electric locomotive.

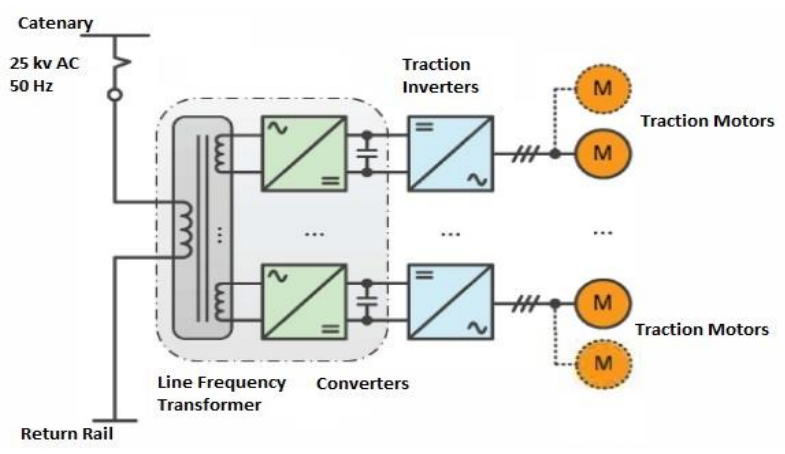

Fig. 5. Conventional Electric Locomotive

\section{A. Hybrid Power electronic transformer based traction}

Line Frequency Transformer (LFT) is also called as locomotive transformer is operating with line frequency of $50 \mathrm{~Hz}$ or $60 \mathrm{~Hz}$. As the operating frequency is inversely proportional to core volume of transformer. Because of this reason volume and mass of locomotive transformer is heavy . The around one third weight of locomotive itself because of this line frequency transformer. On the other hand, with the developments on modern power electronic switching devices , Power Electronic Transformer (PET) based systems now become ultimate solution for the high-speed railway tractions systems and also it enhance the converters with greater power density and efficiency[1]. Figure 6 describe the functional diagram of the Hybrid Power Electronic transformer .

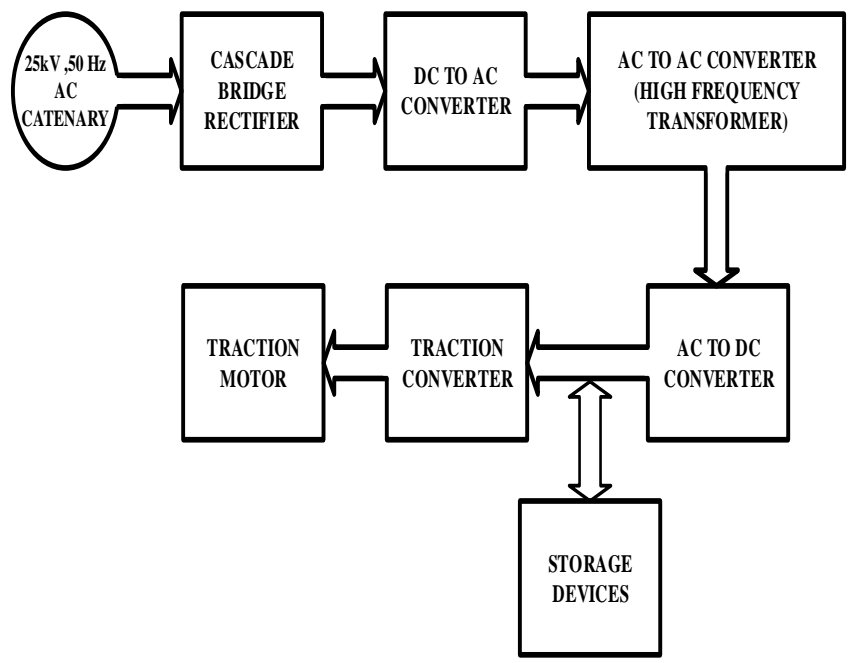

Fig. 6. Hybrid Power Electronic transformer fed traction drive

The high-frequency transformer used in this architecture is to not only for isolation but for weight reduction. The current collection system from the overhead wire through pantograph held up by compressed air pressure on locomotives. Initially, the cascade $\mathrm{H}$ bridge front end converter divides the power modules into various sections, thus $25 \mathrm{kV}$ are directly rectified. The converted high voltage dc voltage is fed to DC to DC converter with a galvanic isolation of high frequency transformer. By the design of this dc to dc converter with high frequency transformer, the total weight of the power circuit unit is considerably reduced. In addition to that high voltage from the overhead line is transformed to suitable load voltage by using a high-frequency transformer and finally fed to traction inverter which drives traction motors fixed on the axle of the locomotives. In previous literature, diesel-based hybrid locomotives were discussed. Earlier locomotives return supply to the grid during regenerative braking mode. In this paper propose, ultra-capacitor based battery storage units connected on the converter section will store energy during regeneration time and this stored energy is utilized by the same locomotive prior to braking. Thus hybrid based pure electric locomotive with a highly efficient drive for high-speed rails is discussed.

\section{B. Direct Coupling to Overhead Equipment}

The coupling to high voltage converters from overhead catenary line is the primary task in electric locomotives [16]. The main reason behind this critical task is because of absence of locomotive transformer at beginning stage . This achieved by interconnecting with various $h$ bridge converter cell [17]. The reduction in voltage stress is also achieved with the help of cascade $\mathrm{h}$ bridge cell[18]. Figure 7 shows the cascade connection of front end $\mathrm{H}$ bridge converter of the locomotive. The decoupling inductance connected between the line-voltage and the converter voltage is equal to the sum of the partial inductances on each cell [18]. The global voltage-drop depending on the line current is based on this inductance.

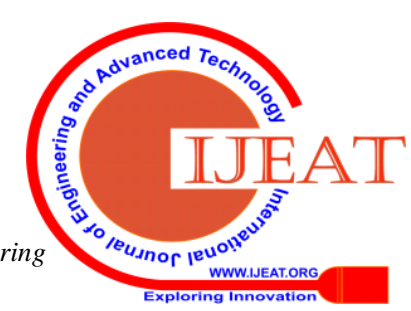




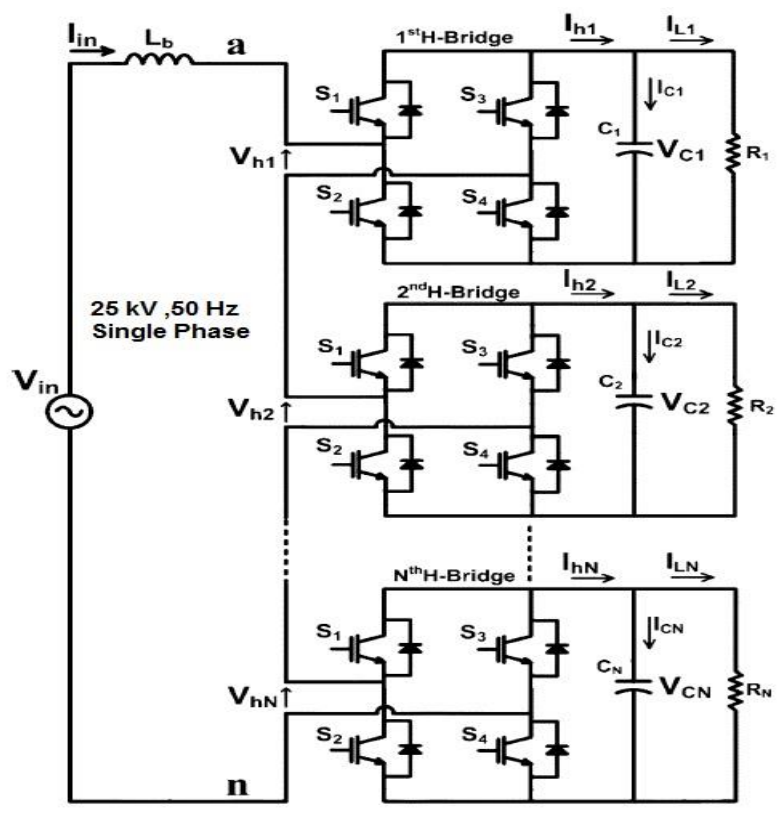

Fig. 7. Cascade front end $\mathrm{H}$ bridge converter

In all cells of cascade connection, the line current is of identical. The critical task on front-end converter is holding high voltage from the overhead equipment directly without any locomotive transformer [19]. The recent trends and development of power semiconductor devices will meet this challenge [19-20]. Since the high voltage high current is utilized for heavy loaded rolling stock, the introduction IGBTs have a significant role among various high power switching devices. The researchers are more focused on the development and design of IGBT working with greater voltage stress. Today there are various types of IGBT are available in the market with a high power rating in both voltage and current.

Recently introduced $6500 \mathrm{~V}$ IGBTs for currents of 200A, 400A, and 600A. All high power IGBTs designed with parallel chips which are covered by a thin aluminum metallization. By using ultrasonic soldering technique connection between IGBT and diodes with aluminum wires are realized[17]. The recent developments on improvement in plasma distribution and reduction of wafer thickness of vertically optimized IGBTs will significantly reduce switching losses and on-state voltages. The IGBT is able to limit its maximum collector current, which depends on the junction temperature and the gate-emitter voltage. These unique characteristics enhance the operation of front end converter as well as on dc to dc converter of power electronic transformer.

\section{Topology Description for High-frequency transformer}

In many of the electrical standards primarily focusing on safety, for that isolated converter play a significant role. In addition to personal safety, separation of load side voltage from high voltage supply also holds key importance. The fine voltage matching is also needed in many applications as it helps in designing and optimizing the voltage rating of different stages in the system. This structure consists of two high-frequency switching DC-AC and AC -DC converter with a high-frequency transformer as shown in Figure 8

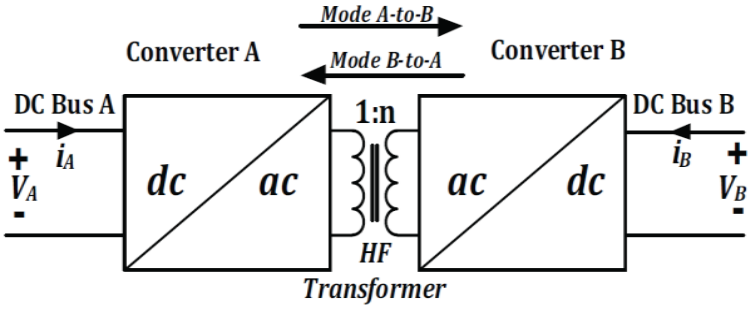

Fig.8. Galvanic isolation using a high-frequency transformer

The operating principle of high-frequency transformers is exactly the same as of standard conventional transformers. The only difference in the operating frequency aspect only, they operate at much higher frequencies than in $50 \mathrm{~Hz}$ or $60 \mathrm{~Hz}$ operating transformers. The main benefits of operating at a higher frequency, the first one are the reduction of the size of the transformer. Since because of smaller size, less copper wire is used, thus reducing the losses and helping to achieve transformer high efficiently. In addition, the core is typically made with ferrite, a wide variety of geometries are available. However, the major advantage brought about by light weight, small size, and higher power density, which meet a number of challenges. Minimizing the common problems such as skin and proximity effects are also considered during the design stage of the high-frequency transformer.

\section{RESULTS AND DISCUSSION}

The performance of Power Electronic Transformer based traction motors have simulated on MATLAB platform. For the simulation, dc to dc converter integrated with high-frequency transformer is carried out. In addition to achieving hybrid models, a storage device performance also carried out during the simulation. The results of stored energy during regenerative mode with discharging are obtained. The Value of State of Charge (SOC) is changing with the DC bus voltage source. If the DC Voltage is more than the nominal voltage of battery then SOC will remain the same (constant) as shown in Figure 10. If the DC voltage is less than the nominal voltage of battery then SOC will decrease.

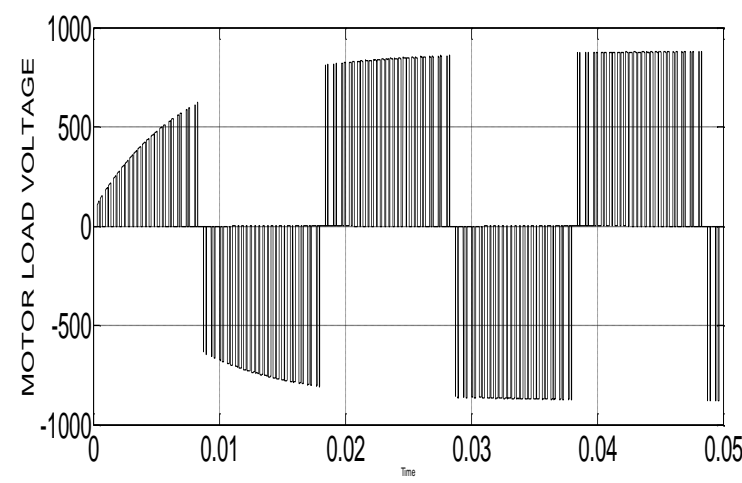

Fig. 9.Load voltage of traction inverter

The simulation on converter inverter arrangement of power electronic transformer with suitable PWM is simulated. 


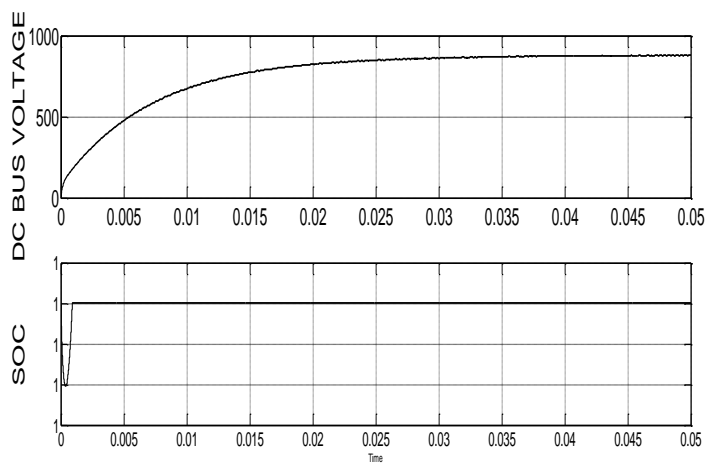

Fig. 10.State of Charge of Storage device

Several configuration of electric locomotive are on recently used with different terminal load voltages. Generally, for dc motor drive and ac motor drives are used in locomotives with terminal voltage between $750 \mathrm{~V}$ and $2000 \mathrm{~V}$. The result of load voltage of traction load inverter as shown in Figure 9. Since because of several switching, The unwanted noise pulse because of several switching sequence on the converters will distort the waveform. To reduction of distortion is achieved by using first order filter. The speed and torque of the induction motor simulation result as shown in Figure 11.

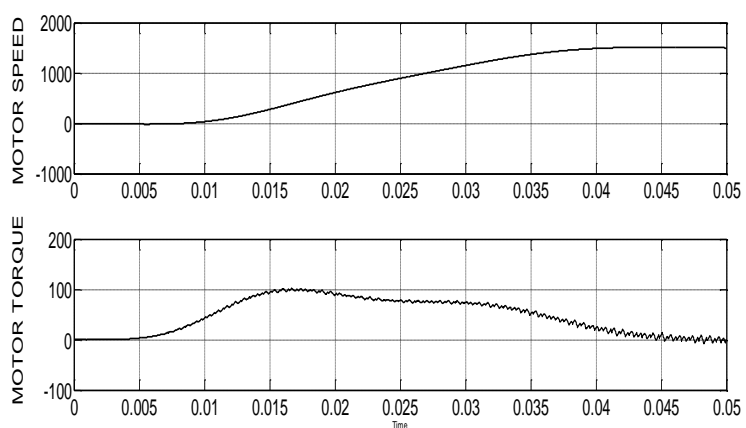

Fig.11. Speed of Traction Motor

\section{CONCLUSION}

In this paper, the Hybrid regenerative system based locomotive with power electronic transformer configuration for the high-speed application is proposed. By storing generated energy during regenerative braking mode is utilized by the same locomotive itself. Configuration with power electronic transformer with a storage medium has verified by simulation using MATLAB platform. The induction motor based load drive is used in this paper. By the combination of variable frequency variable voltage scheme aids to achieve the regeneration on sub synchronous speed. This paper results will highlights an efficient and feasible solution by using power electronic transformer is suitable for high speed rail projects scheme for the recent trends on traction technology

\section{REFERENCES}

1. C Gu,Zedong Zheng, $\mathrm{Y}$ ongdong Li "A Power Electronic Transformer with Multiport Bidirectional Resonant DC DC converters for Electric Traction applications"2015.

2. Deepak Ronanki, Student Member, IEEE, and Sheldon S. Williamson "Evolution of Power Converter Topologies andTechnical Considerations of Power ElectronicTransformer-Based Rolling Stock Architectures" IEEE Transactions on Transportation and Electrification,vol4,no 12018.

3. Sibylle Dieckerhoff, Steffen Bernet, "Power Loss-Oriented Evaluation of High Voltage IGBTs and Multilevel Converters in Transformerless
Traction Applications" IEEE Transactions on power electronic, vol. 20, no. 6, 2005.

4. C Zhao,Darzen Dujic "Power Electronic Traction Transformer-Medium Voltage Prototype" IEEE Transactions on Industrial Electronics,vol 61,no 7 ,pp3257-3268 2014.

5. Ran Liu, Lie Xu, Feipeng Liu, Zedong Zheng, Kui Wang, Yongdong $\mathrm{Li}$ "A Novel Architecture of Urban Rail Transit Based on Hybrid Energy Storage Systems Using Droop Control" IEEE International Conference on Electrical Systems for Aircraft, Railway, Ship Propulsion and Road Vehicles \& International Transportation Electrification 2018

6. X. Lu, K. Sun, J. M. Guerrero, J. C. Vasquez, and L. Huang, "State-ofcharge balance using adaptive droop control for distributed energy storage systems in DC microgrid applications," IEEE Transactions on Industrial electronics, vol. 61(6), pp. 2804-2815, 2014

7. M. Gopikrishnan "Battery/ultra Capacitor Hybrid Energy Storage System for Electric Hybrid and Plug-in Hybrid Electric Vehicles" Middle-East Journal of Scientific Research. 2014.

8. Ruoyu Hou student Member, IEEE, Yinye Yang Member, IEEE, and Ali Emadi Fellow, "Hybrid Electric Locomotive Powertrains" ITEC Asia-Pacific 2014.

9. Soukaina Boudoudouh ; Mohammed Maaroufi "Renewable Energy Sources Integration and Control in Railway Microgrid" IEEE Transactions on Industry Applications vol.55 , no 2, 2019

10. H.Ibrahim and al "Integration of Wind Energy into Electricity Systems: Technical Challenges and Actual Solutions", Energy proceedia, vol. 6, pp. 815_824, 2011.

11. R.Faranda.;S. Leva " Energetic Sustainable.developement of railway stations";. IEEE Power engeneering society general meeting pp 1-6, Tampa, FL, 2007.

12. M. Alvarez-Herault, "Architectures of the distribution futir networks in the presence of decentralized production", Phd thesis, University of Grenoble, 2009.

13. R.R.Pecharroman and al, "Riding the Rails to DC Power Efficiency: Energy efficiency in dc-electrified metropolitan railways", IEEE Electrification Magazine, vol. 2, No.3, pp. 32 - 38, 2014.

14. J.A. Aguado, A.J. Sánchez-Racero and S. de la Torre, Member "Optimal Operation of Electric Railways with Renewable Energy and Electric Storage Systems" IEEE Transactions on Smart Gridn vol. 9 , no. 2, 2018

15. S. de la Torre, A.J. Sánchez-Racero, J.A. Aguado, M. Reyes and O.Martianez, "Optimal sizing of energy storage for regenerative braking inelectric railway systems," IEEE Transactions on Power Systems, vol. PP, no. 99, pp. 1-9, Aug 2014.

16. S. Kouro, M. Malinowski, K. Gopakumar, J. Pou, L. G. Franquelo, B.Wu, 1. Rodriguez, M. A. Perez and J. I. Leon, "Recent advances and industrial applications of multilevel converters " IEEE Transactions on Industrial Electronics, vol. 57, no. 8, pp. 2553-2580, 2010.

17. Carlo Cecati, Antonio Dell'Aquila, Marco Liserre, Vito Giuseppe Monopoli, " Design of H-Bridge Multilevel Active Rectifier for Traction Systems" IEEE Transactions on Industrial Applications,vol 39, no5 2003

18. Steffen Bernet, "Recent Developments of High Power Converters for Industry and Traction Applications" IEEE Transactions on Power Electronics vol 15,no 6, 2000.

19. Jianghua Feng, W. Q. Chu, Senior Member, IEEE, Zhixue Zhang, and Z. Q. Zhu, "Power Electronic Transformer-Based Railway Traction Systems: Challenges and Opportunities" IEEE Journal of emerging and selected topics of power electronics vol 5, no3,2017.

20. Alfred Rufer, Senior Member, IEEE, Nikolaus Schibli, Christophe Chabert, and Claudio Zimmermann "Configurable Front-End Converters for Multicurrent Locomotives Operated on $162=3 \mathrm{~Hz}$ AC and $3 \mathrm{kV}$ DC Systems". IEEE Transactions on Power Electronics vol 18,no 5, 2003.

\section{AUTHORS PROFILE}

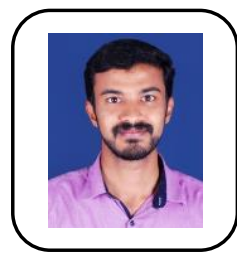

Sachin Gee Paul received the B.Tech degree in Electrical \& Electronics Engineering from M.G University Kerala ,India ,in 2010 and the M.E degree in Power Electronics \& Drives from Anna University Chennai in 2014 where, he is currently doing full time research on the field of Electrical Engineering from Anna Univesity Chennai. He has 4 years of teaching experience.

Published By: 
He published 3 papers in reputed referred International journals and presented 3 papers in International conferences in that area. His research interests include electric locomotives, traction drives ,hybrid vehicles and high power converters.

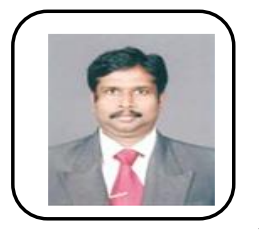

C.S. Ravichandran received the B.E degree in Electrical and Electronics Engineering from Shnmugha College of Engineering , M.E degree in Power Systems from National Institute of Technology(NIT) Trichirapalli and PhD from PSG College of Technology, Coimbatore.He is currently working as Professor in the Department of Electrical and Electronics Engineering at Sri Ramakrishna Engineering College, Coimbatore. He has 26 years of Teaching experience and $21 / 2$ years of Industrial experience.He has published 162 papers in reputed referred International \& National Journals, National \& International conferences. He has guided more than 90 B.E Projects, 25 M.E Projects, 14 Ph.D scholars and is currently guiding $7 \mathrm{PhD}$ Research scholars. His research interests include Power Systems, Control Systems, Power Electronics and Drives and Automation of Energy Management. 